\title{
COVID-19 Pandemi Döneminde Artan Belirsizlik Ortamı ve Kilit Denetim Konuları Açıklamaları Üzerindeki Etkisi: BİST 100 Şirketleri İncelemesi
}

\author{
Increased Uncertainty Environment During the COVID-19 Pandemic \\ Period and Its Effect on Key Audit Matters: BIST 100 Companies Analysis
}

\author{
Deniz Özbay ${ }^{1}$ (1) \\ 'Dr. Öğr. Üyesi, Maltepe Üniversitesi, İşletme ve Yönetim Bilimleri Fakültesi, İstanbul, Türkiye. \\ E-posta: denizozbay@maltepe.edu.tr \\ ORCID: D.Ö. 0000-0003-4643-7577
}

\section{ÖZ}

Denetim raporunun Kilit Denetim Konuları (KDK) bölümünün amacı, paydaşlara denetim sürecindeki önemli ve kritik konular hakkında daha fazla bilgi sunmak ve böylece daha şeffaf ve yüksek kaliteli denetim raporlarının hazırlanmasına katkı sağlamaktır. Denetçi, KDK paragrafında belirsizlik ve risk içeren hususları açıklamaktadır. Bu çalışma, COVID-19 döneminde artan belirsizlik ortamının BİST-100 şirketlerinin KDK bildirimlerine etkisini incelemeyi amaçlamaktadır. Bu amaç doğrultusunda şirketlerin 2019 ve 2020 yıllarına ait KDK açıklamaları karşıllaştırılmış ve sonuçlar yorumlanmıştır. Çalışmada içerik analizi tekniği kullanılmış ve veriler şirketlerin bağımsız denetim raporlarından toplanmıştır. Sonuçlara göre, her iki dönem için de KDK kapsamında en fazla raporlanan konular; hasılatın muhasebeleştirilmesi, finansal araçlar ve maddi duran varlıklar ile ilgilidir. Öte yandan, belirsizlik ortamından en fazla etkilenmesi beklenen muhasebe tahminlerinin KDK içindeki payının arttı̆̆ tespit edilmiş̧ir.

Anahtar kelimeler: Kilit Denetim Konuları, Muhasebe Tahminleri, Bă̆ımsız Denetim Raporları

\section{ABSTRACT}

The Key Audit Matters (KAMs) section of the audit report aims to provide more information to stakeholders about important and critical matters in the audit process, thereby contributing to the preparation of more transparent and high-quality audit reports. The auditor explains any matters relating to uncertainty and risk in the KAM paragraph. This study aims to examine the effect of increasing levels of uncertainty in this environment during the COVID-19 period on the KAMs disclosures of the BIST-100 companies. In line with this purpose, the KAMs disclosures of companies for 2019 and 2020 were compared and the results were interpreted. The content analysis technique was used in the study and data were collected from independent audit reports of companies. According to the results "revenue recognition", "financial instruments", and "property, plant and equipment" were the most frequently reported topics in the KAMs for both periods. Furthermore, it was determined that the share of accounting estimates, which were expected to be most affected by uncertainty, increased in the KAM paragraphs.

Keywords: Key Audit Matters, Accounting Estimates, Independent Audit Reports

Başvuru/Submitted: 15.11.2021 Revizyon Talebi/Revision Requested: 04.01.2022 Son Revizyon/Last Revision Received: 05.01.2022 Kabul/Accepted: 05.01.2022 Sorumlu yazar/Corresponding author: Deniz Özbay / denizozbay@maltepe.edu.tr

Atıf/Citation: Ozbay, D. (2022). COVID-19 pandemi döneminde artan belirsizlik ortamı ve kilit denetim konuları açıklamaları üzerindeki etkisi: BİST 100 şirketleri incelemesi. Muhasebe Enstitüsü Dergisi - Journal of Accounting Institute, 66, 49-63. https://doi.org/10.26650/MED.1023848 


\section{Extended Abstract}

With the effect of globalization and technological developments, significant changes have occurred to the extent and structure of enterprises. Thus, the expectations of stakeholders have changed and the importance of audit reports has increased even more. The recent corporate scandals and international financial crises in particular have caused the expectations regarding audit reports to change. The auditor's report is the final output of the whole audit process. It includes the audited financial statements, footnotes, and the auditor's opinion, and describes both the management and auditor's responsibilities as well as the audit process (ISA 700). However, despite their importance, audit reports have been criticized as being standardized reports that follow the specific formats set in auditing standards and not adequately meeting the needs of financial statement users (Coram \& Wang, 2021, p. 271). Independent audit report users need reports containing companyspecific information rather than the pass-fail model in standard reports (Gold \& Heilmann, 2019, p.12). Because the standardized form of the report does not respond to users' information needs, The International Auditing and Assurance Standards Board (IAASB) published ISA 701 - Communication of Key Audit Matters (KAMs). With new standards, the most significant or noteworthy issues in financial statements have been reported in a separate section of the auditor's report. Its aim was to provide more company-specific information and reduce the expectation gap between auditors and users (Coram \& Wang, 2021, p. 271).

According to ISA 701, the auditor shall determine the matters that required significant auditor attention by taking into account (a) areas of higher assessed risk of material misstatement or significant risks identified in ISA 315, (b) significant auditor judgments relating to areas that involved significant management judgment, including accounting estimates, and (c) the effect on the audit of significant events or transactions that occurred during the period (ISA 701, para.9). Accounting estimates are an important part of financial statements and significantly affect a company's financial position and results of operations (Pinello, Puschaver \& Volkan, 2020, p.26). Even though it consists of a high level of measurement uncertainty, it can give useful information, providing that this is clearly and accurately described and explained (Lau, 202, p.82-83). Auditors should audit any material items about accounting estimates such as measurement of fair value and report them, if any, as KAMs in the independent auditor's report. While the inherent uncertainty in fair value estimates has been mandated to disclosure in the footnote, these provisions indirectly signal the difficulty of audit procedures for fair value estimates. Furthermore, the KAM paragraph in the audit report is important in that it has the potential to affect investors more than footnote disclosures (Christensen, Glover \& Wolfe, 2014, p.72).

Today, the economic and social effects of the Covid 19 pandemic period have reached significant levels. The environment of increased uncertainty in the pandemic period has widened the extent of risky matters in companies. It is unavoidable that this situation will also affect the inherently uncertain accounting estimates. Within the scope of this study, it is aimed to analyze the KAM disclosures of BIST 100 companies and to investigate the effect of the environment of uncertainty of COVID-19 on KAM disclosures. The sample is composed of 100 Turkish companies listed on the Borsa İstanbul BIST-100 Index. The data were collected through content analysis from the independent audit reports of the companies on the Public Disclosure Platform. Within the scope of the research, the KAM disclosures in the independent audit reports of the companies listed in the BIST-100 index were examined and interpreted for 2019 and 2020. In this study are outlined the following research questions:

RQ1. Whether the environment of uncertainty of Covid 19 affects KAM disclosure of companies.

RQ2. Whether there are significant differences between KAM disclosures in different sectors.

RQ3. Whether the independent audit reports including KAMs meet the expectation of containing company-specific information.

According to the results "revenue recognition", "financial instruments", and "property, plant and equipment" were the most frequently reported topics in KAMs for both periods. It was also determined that the share of accounting estimates, which were expected to be most affected by the uncertain environment, considerably increased over the years in KAM paragraphs. 
It was observed that extended reports contained company-specific information as expected. Additionally, it was determined that there were some important differences between the disclosures of the KAMs in different sectors. 


\section{Giriş}

Denetim standartlarına göre, denetimin öncelikli amacı, finansal tablo kullanıcılarının finansal tablolara olan güvenini sağlamaktır. Bu amaca yönelik olarak denetçi, finansal tabloların finansal raporlama çerçevesine uygun olarak hazırlanıp hazırlanmadığına ilişkin görüş sunmaktadır. "Genel amaçl çerçevelerin çoğunda söz konusu görüş, geçerli finansal raporlama çerçevesine uygun olarak finansal tabloların tüm önemli yönleriyle gerçeğe uygun bir biçimde sunulup sunulmadığı veya doğru ve gerçeğe uygun bir görünüm sağlayıp sağlamadı̆̆ hakkındadır” (BDS 200, para.3). Bilginin şeffaf ve güvenilir olması, özellikle yatırımcılar ya da kredi verenler gibi dış paydaşlar açısından son derece önemlidir. Küreselleşmenin ve teknolojinin etkisiyle işletmelerin hacmi ve yapısında önemli değişiklikler meydana gelmiştir. Bu durum, paydaşların işletmelerden olan beklentilerini de değiştirmiştir. Özellikle yakın geçmişte yaşanan şirket skandalları ve finansal krizler denetim raporlarına ilişkin beklentilerin de değişmesine neden olmuştur. Bağımsız denetim raporlarının önemi her geçen gün artarken, bağımsız denetim faaliyetlerinde revizyona gidilmesi ihtiyacı ortaya çıkmışır. Bağımsız denetim raporlarına ilişkin değişen beklenti ve ihtiyaçlar doğrultusunda, Uluslararası Denetim ve Güvence Standartları Kurulu (The International Auditing and Assurance Standards Board - IAASB) Ocak 2015'te, "ISA 701 Communicating Key Audit Matters in the Independent Audıtor's Report" standardını yayımlamıştır. Buna paralel olarak Kamu Gözetimi Muhasebe ve Denetim Standartları Kurulu (KGK), BDS 701- Kilit Denetim Konularının Bağımsız Denetim Raporunda Bildirilmesi başlıklı Bağımsız Denetim Standardının ilk sürümünü, 01.01.2017 tarihinde ve sonrasında başlayacak hesap dönemlerinin denetiminde uygulanmak üzere, 09.03.2017 tarihli ve 30002 sayılı Resmi Gazete’ de yayımlamıştır. Kilit denetim konuları (KDK), denetimin yürütülmesi sırasında azami düzeyde dikkat edilmesini gerektiren konuları belirlemektedir. KDK, ciddi riskli olarak belirlenen alanlar yanında, yüksek derece belirsizlik içeren muhasebe tahminlerini ve yönetimin önemli yargılarını içeren finansal tablo alanlarına ilişkin denetçi yargılarını da kapsamaktadır (BDS 701, para.9). Günümüzde COVID-19 pandemi döneminin ekonomik ve sosyal etkileri önemli boyutlara ulaşmıştır. Pandemi nedeniyle artan belirsizlik ortamının, işletmelerde riskli görülebilecek konuların kapsamını genişletmesi ve muhasebe tahminlerini etkilemesi de kaçınılmaz olmaktadır. Bu çalışma kapsamında, işletmelerin KDK açıklamalarının analiz edilmesi ve pandeminin yarattığı belirsizlik ortamının KDK açıklamalarına etkisinin araştırılması amaçlanmaktadır.

\section{Kilit Denetim Konuları}

Denetim raporları, denetim standartlarıyla belirlenen ve denetim raporlarında yer alması gereken, standartlaşmış ve bu nedenle de iletişim kabiliyeti azalmış kalıplara sahip olmaları nedeni ile uzun süredir eleştirilmektedir (Coram ve Wang, 2020, s. 71). Oysaki denetim raporlarının şirkete özgü olması ve rapor kullanıcılarına daha detaylı bilgi sunması beklenmektedir. Bağımsız denetim raporu kullanıcıları, standart raporlarda yer alan geçti-kaldı (pass-fail) modelinden ziyade şirkete özgü bilgiler içeren raporlara ihtiyaç duymaktadır (Gold ve Heilmann, 2019, s.12). Bağımsız denetim raporlarına ilişkin değişen beklenti ve ihtiyaçlar doğrultusunda, Uluslararası Denetim ve Güvence Standartları Kurulu (IAASB), 2011 yılında, denetim raporlarına olan güveni tazelemek ve raporların iletişim gücü ve anlaşllabilirliğini artırmak amacıyla, IAASB-Denetçi Raporu Projesi’ni başlatmıştır (Yanık ve Karataş, 2017, s.5). Yaklaşık 10 yıllık süreç içinde bağımsız denetim raporlarında önemli revizyonlar yapılırken, yeni bağımsız denetim standartları da oluşturulmuştur. Bunlardan biri de IAASB tarafindan Ocak 2015'te yayımlanan "ISA 701 Communicating Key Audit Matters in the Independent Audıtor's Report" standardıdır. Buna paralel olarak ülkemizde, Kamu Gözetimi Muhasebe ve Denetim Standartları Kurulu (KGK) tarafından BDS 701- Kilit Denetim Konularının Bağımsız Denetim Raporunda Bildirilmesi başlıklı Bağımsız Denetim Standardı yayımlanmıştır. BDS 701 standardının ilk sürümü, 01.01.2017 tarihinde ve sonrasında başlayacak hesap dönemlerinin denetiminde uygulanmak üzere, 09.03.2017 tarihli ve 30002 sayılı Resmi Gazete' de yayımlanarak yürürlüğe girmiştir. Denetim standartlarında yapılan düzenlemeler ile denetçinin işletmeye özgü kritik öneme sahip ya da riskli gördüğü hususları açıkladığı KDK bölümü, denetim raporlarında ayrı bir bölüm olarak raporlanmaktadır. Bu konuların ayrı bir başlık altında bildirilmesinin amacı, yürütülen denetime ilişkin daha fazla şeffaflık sağlayarak denetçi raporunun iletişim değerinin artırılmasıdır (BDS 701, para.2). KDK raporlamasıyla, denetçi ile işletme ve denetim komitesi arasındaki iletişimin artması, finansal tablolardaki önemli bilgilere dikkat çekilmesi, böylece daha şeffaf ve kaliteli denetim raporlarının ortaya çıkması hedeflenmiştir (Kavut ve Güngör, 2018, s. 60). KDK, aynı zamanda, 
bilgi kullanıcısına o işletmeyle ilgili bir ekonomik karar alacağı zaman üstünde durması gereken önemli kısımları belirtmesi bakımından da önem taşımaktadır (Akdoğan ve Kılıç, 2021, s. 2). KDK ile ortaya çıkan şeffaflık ve hesap verebilirlik baskısının, yöneticilerin kararlarını daha dikkatli almalarına neden olarak, finansal raporlama kalitesinin iyileştirilmesine katk1 sağlaması beklenmektedir (Gold, Heilmann, Pott, ve Rematzki, 2020, s. 234). Bu nedenle, bu bölümün denetime ilişkin çıkar gruplarının beklentilerine cevap vererek, beklenti farklarını azaltmaya da katkı sağlayacağı düşünülmektedir (Sarısoy ve Kepçe, 2019, s.48).

KDK'da yer alacak başlıkların belirlenmesinde, üst yönetimden sorumlu olanlara bildirilen konular arasından, denetçinin muhakemesine göre, cari döneme ait finansal tabloların denetiminde en çok önem arz eden konular seçilmektedir. (BDS 701, para. A9). Karşılaştırmalı finansal tablolar sunulmuş olsa dahi KDK bölümü cari döneme ait finansal tabloların denetiminde en çok önem arz eden konularla sınırlıdır. Bunun yanında, konunun denetimdeki önemi, konunun denetim kapsamında ele alınış şekli ve denetim prosedürlerinin de denetçi tarafından ilgili finansal tablo dipnotlarına referans verilerek açıklanması gerekmektedir (Türel ve Türel, 2019, s. 1268-1269). Standartta denetim raporunda yer alacak KDK'lar için herhangi bir sayı verilmemekle birlikte, denetçinin denetim raporunda en az bir tane kilit denetim konusunun belirmesi; bildirilecek bir konu tespit edilmemesi halinde ise bu durumun KDK bölümünde açıklanması beklenmektedir (BDS 701, para.14). İşletmenin sürekliliği konusunda bir şüphe bulunması halinde buna ilişkin nedenler ile olumlu görüş dışında görüş verilmesine neden olan konuların, mahiyeti gereği denetimde kilit öneme sahip olmalarına karşın, ayrı bir kısımda sunulmaları gerekmektedir (BDS 701, para. 15).

\section{Geçmiş Literatürün İncelenmesi}

Denetim raporlarında KDK başlıklarının ayrı olarak raporlanmasının raporların şeffaflı̆̆ına katkı sağlayarak, denetimin kalitesini artırması hedefi bazı araştırmacılar tarafından kabul görürken, bazıları tarafından eleştirilmektedir. Eleştirilerin temel dayanağını, işletme için kritik önem arz eden konuların zaten finansal tablo dipnotlarında detaylı olarak açıklandığı görüşü oluşturmaktadır. Bazı ülkelerde, örneğin Polonya'da, bağımsız denetim raporları yanında denetçi tarafından pay sahiplerini ilgilendiren bilgilerin yer aldığı ayrı bir rapor düzenlenmekte; benzer şekilde Fransa'da da 2003 yılından bu yana genişletilmiş denetim raporları (Justification of Assessments - JOA) kullanılmaktadır (Cordoş ve Fülop, 2015, s. 130). Bédard, Gonthier-Besacier, ve Schatt (2014), bu konunun altını çizerek, KDK’nın fayda ve maliyetlerini analiz etmek üzere JOA ile denetim kalitesi, denetimin maliyeti ve denetimin verimliliği arasındaki ilişkiyi araştırmışlardır. 2000-2011 yılları arasında 120 şirket üzerinde yapılan araştırma sonuçlarına göre denetçiler tarafından sağlanan ek bilgilerin, finansal piyasalardaki karşıllğının zayıf olduğuna dair bulgulara ulaşılmıştır. Ancak, bağımsız denetim raporu kullanıcılarının, KDK ile birlikte raporların iletişim gücünün artacağına dair beklentileri de araştırmalar kapsamında ön plana çıkmaktadır. Cordoş ve Fülop (2015), denetim raporu kullanıcılarının, KDK ile ilgili algılarını ölçmeye yönelik olarak, IAASB tarafından 2013 yılında yayımlanan taslak metne gelen yorumları içerik analizi ile incelemiştir. Araştırma sonuçlarına göre, yorum mektuplarının ağırlıklı kısmında KDK önemli bir kavram olarak değerlendirilirken, KDK'nın raporlama sürecine olumlu bir katkı sağlayacağı beklentisi öne çıkmaktadır. Aynı varsayım doğrultusunda Christensen, Glover ve Wolfe (2014), KDK'nın ayrı bir paragrafta bildirilmesinin, profesyonel olmayan yatırımcıların kararlarına etkisini araştırmışlardır. 141 katılımcı ile gerçekleştirilen çalışmada, KDK'nın ayrı bir bölüm halinde sunulduğu raporları kullanan yatırımcıların, standart bir denetim raporu alan veya yönetimin dipnotlarında aynı KDK bilgisini alan yatırımcılara göre, KDK bildirimlerine bağlı olarak yatırım kararlarını değiştirme olasılıklarının daha yüksek olduğu sonucuna ulaşılmıştır. Gold ve Heilmann (2019), KDK ile ilgili 22 çalışmanın sonuçlarını analiz etmiştir. Analiz sonuçları, KDK raporlamasının, özellikle profesyonel olmayan yatırımcılarla ilgili olarak, finansal tablo kullanıcılarının kararlarını etkileme, ayrıca yöneticilerin kazanç yönetimi girişimlerini azaltma potansiyeline sahip olduğunu desteklemektedir. Öte yandan, KDK açıklamaları ile daha geniş bir sermaye piyasası tepkisi arasında anlamlı bir ilişki tespit edilemezken, KDK açıklamalarının denetim ücretleri, denetim gecikmeleri gibi bazı olumsuz sonuçlarının da olabileceği tespit edilmiştir. Son olarak, yöneticilerin denetçileriyle bilgi paylaşma istekliliği ve risk alma davranışlarının KDK açıklamalarından etkilendiği yönünde bulgulara ulaşıılmıştır. 
Gold, ve ark. (2020), denetçi raporlarında KDK uygulanmasının yöneticilerin raporlama davranışına etkilerini araştırmıştır. $\mathrm{Bu}$ çalışmada, KDK aracılığıyla artan şeffaflığın, yöneticiler üzerindeki hesap verebilirlik baskısını arttırdığı ve raporlama kalitesinin de buna bağlı olarak iyileşeceği varsayımından hareket edilmektedir. Bulgular, yöneticilerin agresif bir finansal raporlama kararı verme eğilimlerinin KDK varlı̆̆ında, KDK yokluğuna kıyasla azaldığını göstermektedir. Dolayısıyla bulgular, KDK'nın agresif finansal raporlama davranışını azaltarak, finansal raporlama kalitesini arttırdığı varsayımını desteklemektedir. KDK ve denetim kalitesi arasındaki ilişkiyi ampirik olarak inceleyen bir diğer çalışma Kitiwong ve Sarapaivanich (2020) tarafından gerçekleştirilmiştir. Tayland'da faaliyet gösteren 312 şirket üzerinde yapılan araştırmada, KDK uygulamasına geçmeden önceki iki yıl ile geçtikten sonraki iki yılın verileri karşılaştırılmaktadır. Çalışma sonucunda, KDK'nın denetim kalitesini iyileştirdiğine dair zayıf bulgular elde edilirken, KDK sayısı ve çeşidinin denetim kalitesi üzerinde anlamlı bir etkisinin bulunmadığı yönünde bulgulara ulaşılmıştır. Ferreira ve Morais (2019) ise, denetlenen şirketlerin özelliklerinin raporlanan KDK sayısını etkileyip etkilemediğini araştırmak amacıyla, Brezilya'da faaliyet gösteren halka açık 447 şirketin bağımsız denetim raporlarını incelemiştir. Araştırma sonuçlarına göre, KDK sayısı ile hem denetçinin Big4 olması hem de denetlenen şirketin karmaşıklığı arasında pozitif bir ilişki tespit edilmiştir. Bunun yanında, denetçi ücretleri ve denetçi görüşü ile KDK sayısı arasında ise negatif bir ilişki tespit edilmiştir.

Pinello, Puschaver ve Volkan (2020) da önemli muhasebe tahminleri ve KDK arasındaki ilişkiyi araştırmışlardır. Dow Jones 30 Sanayi endeksinde yer alan şirketlerin 2017 yılı açıklamalarıyla gerçekleştirilen çalışmada, muhasebe tahminlerinin, KDK bildirimlerinin önemli bir parçasını oluşturduğu sonucuna ulaşıılmıştır. Benzer şekilde Lau (2021) ise KDK ve muhasebe tahminleri arasındaki ilişkiyi incelemiştir. Çalışma, aynı zamanda, ölçüm belirsizliği ve yönetim yanlılığının denetçi üzerindeki etkisini araştırmaktadır. Çin'de borsaya kote 351 işletme ile yapılan araştırmanın bulguları muhasebe tahminlerinin KDK içinde yüksek oranda raporlandığını doğrularken, belirsizlik ölçümünün, muhasebe tahminlerini içeren KDK raporları ile pozitif, yönetim yanlılı̆̆ının ise negatif ilişki içinde olduğu tespit edilmiştir. Öte yandan muhasebe tahminlerini KDK içinde raporlayan işletmelerde, muhasebe tahminlerinin raporlanan kazancın değeri ya da uygunluğunu arttırdığ yönünde bir kanıt elde edilmemiştir.

Fera, Pizzo, Vinciguerra, ve Ricciardi (2021), KDK ile kurumsal yönetim arasındaki ilişkiye odaklanmaktadır. Çalışma, iç kurumsal yönetim mekanizmalarının kalitesi ile dış denetçiler tarafından raporlarında açıklanan KDK'lar arasındaki ilişkiyi analiz etmektedir. Çalışma, İtalyan Menkul Kıymetler Borsası'nda işlem gören ve finansal olmayan 118 şirketin 2017-2019 yılları arasındaki üç yıllık bağımsız denetim raporlarından ele edilen verilerin ampirik analizi ile gerçekleştirilmiştir. Bulgulara göre, yüksek kaliteli ve sürdürülebilir bir kurumsal yönetim sistemine sahip firmaların, yüksek kaliteli kurumsal yönetim sistemine sahip olmayan firmalara göre, denetim sürecinden kaynaklanan ve daha sonra denetim raporunda açıklanan KDK sayılarının daha az olduğu sonucuna ulaşılmıştır.

Coram ve Wang (2021) ise, KDK'nın beklenti farkları üzerindeki etkisini araştırmışıtır. 240 denetim raporu kullanıcısı ile yapılan araştırmanın sonuçlarına göre, denetim raporlarına KDK’nın eklenmesinin, denetçi sorumluluğu ve denetçi güvenirliği konularındaki alg1 üzerinde anlamlı bir etkisi olmadığı tespit edilmiştir.

Türkiye'de yapılan çalışmalar ise ampirik olmaktan ziyade daha çok içerik analizi vasıtasıyla mevcut durum tespitine dayanmaktadır. Örneğin, Kavut ve Güngör (2018), BİST-100 şirketlerinin 2017 yılında bağımsız denetim raporlarında yer alan KDK bildirimlerini içerik analizi ile incelemiştir. Çalışma kapsamında şirketlerin sektörel dağılımları, denetim firmalarının dağılımı, denetim görüşü tiplerinin dağılımları ve çevresel açıklamaların sektörel dağılımları olmak üzere beş konu analiz edilmiştir. Çalışma bulgularına göre BİST-100 işletmelerinin 2017 yılında en çok hassılatın muhasebeleştirilmesi, şerefiye/sınırsız ömürlü maddi olmayan duran varlıklar değer düşüklüğü testleri, ticari alacaklar, stoklar/stok değer düşüklükleri ve kredi ve alacaklarda sınıflama ve değer düşüklüğü konularında KDK bildirimi yaptıkları tespit edilmiştir. Gökgöz (2018) de Borsa İstanbul'da işlem gören140 adet şirketin 2017 mali yılına ilişkin bağımsız denetim raporlarında yer alan KDK bildirimlerini incelemiştir. Çalışma sonuçlarına göre denetim raporlarında en çok belirlenen kilit denetim konuları sırayla; hasılat, ticari alacaklar, stoklar, maddi duran varlıklar ve yatırım amaçlı gayrimenkuller olarak tespit edilmiştir. Benzer şekilde, Akdoğan ve Bülbül (2019) de BIST 100 endeksinde yer alan firmaların 2017 yılına ait bağımsız denetim raporlarını inceleyerek, ilk uygulama sonuçlarını değerlendirmiştir. BİST-100 şirketleri, KDK bildirimleri yanında, 
denetçi firma, görüş türü, KDK sayısı bakımından da analiz edilmiştir. Çalışma sonuçlarına göre en çok KDK bildirimleri; hasılat, maddi ve maddi olmayan duran varlıkların değerlemesi ve karşıllklar/yükümlülükler olarak sıralanmıştır. Çalışmada ayrıca KDK kapsamında yer alan bildirim konuları 20 ana başlık altında toplanarak, bu konulara ilişkin denetim prosedürlerine de yer verilmiştir. KDK açıklamalarının bağımsız denetim raporlarında ayrı bir bölüm olarak yer aldığı ilk uygulama yılı olan 2017 yılı bağımsız denetim raporlarını inceleyen bir diğer çalışma ise Karacan ve Uygun (2018) tarafından gerçekleştirilmiş̧ir. Reel sektörde faaliyet gösteren 62 şirketin bağımsız denetim raporlarında yer alan KDK açıklamalarının incelendiği çalışmada, toplam 134 adet KDK tespit edilirken, en çok açıklanan konular; maddi ve maddi olmayan duran varlıkların gerçeğe uygun değerlerinin tespiti ve bu varlıkların değer düşüklüğü, hasılatın muhasebeleştirilmesi ve ticari alacakların geri kazanılabilirliği olmuştur. Ciğer, Vardar, ve Kınay (2019), yine 2017 yılına ait bağımsız denetim raporlarını incelerken, daha geniş bir örneklem kullanmıştır. Çalışmada, Borsa İstanbul'da faaliyet gösteren 515 şirketin 2017 hesap dönemine ait bağımsız denetçi raporlarındaki KDK açıklamaları incelenmiş, sektörlere ve denetim firmalarına göre frekans analizleri gerçekleştirilmiştir.

Sarısoy ve Kepçe (2019) KDK'ya ilişkin bağımsız denetim raporu kullanıcılarının görüşlerini inceleyerek, çıkar grupları arasında beklenti farkı olup olmadığını araştırmışlardır. 362 katılımcı ile anket tekniği kullanılarak gerçekleşen araştırmada bağımsız denetçilerin, işletme yöneticilerinin, aracı kurum yöneticilerinin ve bankaların kredi tahsis birimlerinde çalışan yöneticilerin kilit denetim konularına ilişkin olarak önemli beklenti farklılıklarının olduğu tespit edilmiş̧ir. Kilit denetim konularını en faydalı bulan kesim, denetim raporunun kullanıcıları olan banka ve aracı kurum yöneticileri olmuştur.

Türel ve Türel (2019), Borsa İstanbul'da işlem gören şirketlerin 2017 ve 2018 yıllarına ilişkin bağımsız denetim raporlarını ve bu raporlarda yer alan KDK açıklamalarını incelemiş ve KDK açıklamalarını finansal raporlama standartları çerçevesinde sınıflandırmıştır. 776 adet bağımsız denetim raporunun incelendiği çalışmada, 2017 yılı için 819; 2018 yılı için 777 adet olmak üzere toplam 1596 adet KDK açılamasına yer verildiği tespit edilmiş̧ir. KDK kapsamında en çok yer alan konuların ise; finansal araçlar, hasılat, maddi duran varlıklar, stoklar ve varlıklarda değer düşüklüğü olduğu tespit edilmiştir. Benzer şekilde Akdoğan ve Kılıç (2021), Borsa İstanbul'da işlem gören 426 işletmenin 2019 yılı bağımsız denetim raporlarını, raporlarda yer alan bağımsız denetçi görüşleri, kilit denetim konuları, olumlu görüş dışındaki görüşlerdeki dayanak noktalarını ve görüşü veren bağımsız denetçileri istatistiksel olarak incelenmiştir. Çalışma sonuçlarına göre, bağımsız denetim raporlarında en çok bildirilen konu hasılatın muhasebeleştirilmesi olarak tespit edilmiştir.

Erdem (2020), finansal tablolarda sunulan bilgilerde hile yapılma olasılı̆̆ııın, bağımsız denetim raporlarında açıklanan KDK'lara etkisini ampirik olarak araştırmıştır. BIST-100 de işlem gören 85 şirketin 2018-2019 yıllarına ait bağımsız denetim raporlarında yer alan KDK açıklamalarından elde edilen veriler genelleştirilmiş sıralı logit model kullanılarak analiz edilmiştir. Bulgular, yıllar itibariyle KDK sayısı ve içeriğinin nitelikli olarak takibinin denetim kalitesini arttırmada etkili olduğu yönündeki görüşü desteklemektedir.

Sarısoy (2021) tarafından gerçekleştirilen çalışmada ABD ve Türkiye, KDK açıklamaları bakımından karşılaştııılmıştır. Çalışma sonuçlarına göre, genel olarak ülkemizde daha fazla sayıda KDK bildirimi yapıldığı, KDK bildirimlerinde dada uzun açıklamalara yer verildiği ve bildirilen konular arasında kategorik farklar olduğu tespit edilmiştir.

Süer (2021), KDK bildirimlerinin muhasebe tahmin ve varsayımlarıyla ilişkisini incelemiştir. BİST 30 şirketlerinin 2019 yılı bağımsız denetim raporları kapsamında gerçekleştirilen incelemede, önemli muhasebe tahmin ve varsayımlarının \%24'ünün KDK kapsamında bildirildiği, incelemeye konu şirketlerin denetim raporlarında yer alan KDK bildirimlerinin ise \% 71 oranında finansal tablo dipnotlarında önemli muhasebe tahmin ve varsayımı olarak açıklandığı tespit edilmiştir.

\section{BİST-100 Şirketlerinin 2019 ve 2020 Yıllarına Ait KDK Bildirimlerinin İncelenmesi}

\subsection{Araştırmanın Amacı ve Önemi}

Araştırmanın amacı, COVID-19 döneminde artan belirsizlik ortamının, işletmelerin KDK bildirimlerine olan etkisini incelemek, KDK bildirimlerini sınıflandırmak ve sektörel farklılıkları ortaya koymaktır. COVID-19 pandemisinin Dünya 
genelinde önemli sosyal ve ekonomik etkileri olmuştur. Çalışma hayatında alışılagelmiş düzen ile işletmelerin varlığını devam ettirme imkânları azalırken, değişen Dünya düzeninde teknolojik yatırımların ve dijitalleşmenin önemi çok net bir şekilde ortaya çıkmıştır. Pandemi süreci günümüzde hala belirsizliğini korurken, bu durum işletmelerin stratejik karar alma sürecini de yakından etkilemektedir. Belirsizlik ortamı, işletmelerde risk unsuru taşıyan konuların ağırlığını da artırmıştır. Dolayısıyla, risk odaklı yapısı gereği denetim sürecinin de belirsizlik ortamından etkilenmesi kaçınılmazdır. Denetçi, belirsizlik içeren ve risk oluşturabileceği düşünülen konuları KDK olarak tanımlamakta, gerekçelerini açıklamakta ve ilgili hesaplara ve dipnotlara atıfta bulunmaktadır. Bağımsız denetim raporlarında belirsizlik içeren konuların temelini ise muhasebe tahminleri oluşturmaktadır. Muhasebe tahminleri, finansal tablolardaki ölçüm belirsizliği içeren parasal tutarlardir (KGK, 2021: para.5). Finansal raporlamada muhasebe tahminlerinin önemi günden güne artarken, muhasebe tahminleri yapısında ölçüm belirsizlikleri ve yönetim yargıları olmak üzere iki temel problem taşımaktadır (Lau, 2021, s.79). Doğası gereği zaten belirsizlik taşıyan muhasebe tahmin ve varsayımlarının bağımsız denetim sırasında denetçi için önem arz eden konular arasında yer alması ve KDK bildirimlerine yansıması beklenmektedir (Süer, 2021, s. 23). Tahminlere ilişkin dipnotlar daha geniş ve ayrıntılı bilgi ve analizler içerirken, KDK içinde bu konulara ana hatlarıyla yer verilmesi, denetçi tarafından konunun önemine vurgu yapılması bakımından önem taşımaktadır (Christensen, ve ark., 2014, s. 74). Dolayısıyla, KDK bölümü içindeki muhasebe tahminlerinin ağırlı̆ı, COVID-19 pandemi döneminin KDK bildirimleri üzerindeki etkisini analiz etmek adına önemli bir gösterge olarak karşımıza çıkmaktadır. Ayrıca, KDK, her ne kadar işletmeler özelinde, denetçinin muhakemesine bağlı olarak en önemli, kritik ya da riskli konuları içerse de, işletmelerin bağımsız denetim raporlarının bir bütün halinde incelenerek sonuçların yorumlanması, genel olarak sektörlerdeki ya da piyasalardaki önemli problemlerin ortaya çıkarılması açısından da önem arz etmektedir.

\subsection{Araştırmanın Kapsamı ve Yöntemi}

Araştırma kapsamında, BİST-100 endeksinde işlem gören şirketlerin, 2019 ve 2020 yılı bağımsız denetim raporlarında yer alan KDK bildirimleri incelenmiş ve yorumlanmıştır. Veriler, şirketlerin Kamuyu Aydınlatma Platformu'nda (KAP) yer alan bağımsız denetim raporlarından içerik analizi ile toplanmıştır. Araştırma kapsamında üç temel soruya cevap aranmaktadır. Bunlardan ilki COVID-19 ile birlikte artan belirsizlik ortamının KDK kapsamında yapılan açıklamalar üzerindeki herhangi bir etkisinin olup olmadığıdır. Bu çerçevede işletmelerin pandemi öncesi (2019) bağımsız denetim raporlarında yer alan KDK bildirimleri ile pandemi sonrası (2020) KDK bildirimleri frekanslar aracılığ 1 ile karşılaştırılmıştır. Artan belirsizlik ortamının muhasebe tahmin ve varsayımlar üzerindeki etkisini tanımlayabilmek için, muhasebe tahmin ve varsayımları kapsamındaki KDK bildirimleri, yıllar itibariyle ayrıca karşılaştırılmıştır. İkinci olarak, KDK kapsamında açıklanan konuların sektörlere göre dağılımda önemli farklılıklar olup olmadığı araştırılmıştır. Bu kapsamda, KDK bildirimleri her iki yıl için sektör bazlı ayırıma tabi tutularak, önemli sektörel değişiklikler tespit edilmiştir. Son olarak, çalışma kapsamında, KDK içeren bağımsız denetim raporlarının, işletmeye özgü olması beklentisini sağlayıp sağlamadığı sorusunun cevabı aranmıştır. Bu bağlamda bağımsız denetim raporları, raporu düzenleyen denetim firmasına göre sınıflara ayrılmış ve aynı denetçiler tarafından düzenlenen raporlarda benzerlik ve farklılıkların düzeyi araştırılmıştır.

\subsection{Araştırma Bulguları}

Araştırma kapsamına alınan BİST-100 şirketlerini ve bağımsız denetim firmalarını içeren tablolara Ek 1'de yer verilmiştir. 2019 yılında BİST-100 şirketlerinin bağımsız denetim raporlarını düzenleyen denetim şirketlerinin sayısı 16; 2020 yılında ise 15'tir. Araştırma bulgularına göre, 2019 yılında BISTT-100 şirketleri tarafından KDK bölümünde raporlanan 198 konu tespit edilirken, 2020 yılında açıklanan KDK sayısı 216'ya yükselmiştir. Dolayısıyla, 2019 yılında ortalama KDK sayısı 1,98 iken; 2020 yılında 2,16 olarak hesaplanmıştır. KDK sayısı ile denetçi firma ya da denetim görüşü arasındaki ilişki ayrıca incelenmiştir. 2019 yılında 14 bağımsız denetim raporunda şartlı (sınırlı olumlu) görüş bildirilirken, 2020 yılında, 11 bağımsız denetim raporunda şartlı (sınırlı olumlu) görüş beyan edilmiştir. Açıklanan KDK sayıları 1 ile 7 arasında değişmektedir. Şartlı (sınırlı olumlu) görüş içeren raporlarda yer alan KDK sayıları ise 1 ile 4 arasında değişmektedir. Dolayısıyla, KDK sayısının denetim görüşüne göre değişmediği görülmektedir. 
2020 yılında KDK kapsamında yer alan 216 konun 167 tanesi; 2019 yılındaki 198 adet KDK bildiriminin ise 166 tanesi Big4 firmalarına ait bağımsız denetim raporlarında yer almaktadır. Big4 olarak tanımlanan denetim firmalarının ortalama KDK bildirimi sayısı 2020 yılında 2, 06; 2019 yılında ise 2,16 olarak hesaplanmıştır. Aynı dönem diğer denetim firmalarının ortalama bildirim sayısı ise sırasıyla 2,47 ve 1,39 olarak gerçekleşmiştir. Big4 firmaları içinde en fazla KDK bildirimi KPMG tarafından gerçekleştirilmiştir. Sonuçlar bir bütün olarak yorumlandığında denetçi firmaya göre, KDK kapsamında bildirilen konu sayısının değiştiğine dair güçlü bir kanıt elde edilmemiştir. Denetim şirketlerinin ortalama KDK bildirimi sayılarına Tablo l'de yer verilmiştir.

Tablo 1: KDK Bildirimlerinin Bağımsız Denetim Şirketlerine Göre Dağılımı

\begin{tabular}{|l|c|c|c|c|c|c|}
\hline \multirow{2}{*}{$\begin{array}{l}\text { Bağımsız Denetim } \\
\text { Şirketi }\end{array}$} & \multicolumn{3}{|c|}{$\mathbf{2 0 2 0}$ Yılı } & 2019 Yılı \\
\cline { 2 - 7 } & BDR Sayısı & KDK Sayısı & Ortalama & BDR Sayısı & $\begin{array}{c}\text { KDK } \\
\text { Sayısı }\end{array}$ & Ortalama \\
\hline PWC & 31 & 59 & 1.90 & 27 & 55 & 2.04 \\
\hline EY & 22 & 41 & 1.86 & 21 & 42 & 2.00 \\
\hline KPMG & 14 & 40 & 2.86 & 14 & 40 & 2.86 \\
\hline DELOITTE & 14 & 27 & 1.93 & 15 & 29 & 1.93 \\
\hline Dï̆ĞER & 81 & 167 & 2.06 & 77 & 166 & 2.16 \\
\hline
\end{tabular}

2019 ve 2020 yıllarında, BİST-100 işletmelerinin bağımsız denetim raporlarında yer alan KDK açıklamalarında çok sayıda farklı ifadeye yer verilmiş olup, bu açıklamalar temel başlıklar altında toplanarak, KDK bildirimlerinin sayısı ve konunun tüm bildirimler içindeki yüzdesel ağırlığı Tablo 2'de gösterilmiştir. Denetim şirketleri tarafından 2019 ve 2020 yıllarında en çok KDK kapsamında değerlendirilen konu hasılatın muhasebeleştirilmesi olmuştur. Hasılatın muhasebeleştirilmesi konusunun KDK içinde ayrıca belirtilmesinin nedenleri olarak; edim yükümlülüklerinin yerine getirilip getirilmediğinin tespitinde yaşanan zorluklar, tamamlanma yüzdesinin tespitinde yaşanan zorluklar ve hasılatın finansal tablodaki ağırlı̆g 1 nedeni ile oluşan riskler öne çıkmaktadır. KDK kapsamında en çok raporlanan ikinci konu başlığı ise finansal araçlardır. Finansal araçlar başlığı altında en çok açıklanan konular; kredilere ilişkin değer düşüklüğü, finansal yatırımlarda gerçeğe uygun değer ölçümü ve finansal varlık/yükümlülüklerde gerçeğe uygun değer ölçümü olarak sıralanmaktadır. Bir diğer önemli KDK başlığı ise maddi duran varlıklardır. Bu başlık altından en çok, maddi duran varlıklar değer düşüklükleri ve yeniden değerleme açıllamalarına yer verildiği görülmektedir. KDK bölümünde en çok bildirilen diğer konu başlıkları ise; ticari alacakların geri kazanılabilirliği, şerefiye değer düşüklüğü, maddi olmayan duran varlıklar (değer düşüklükleri ve aktifleştirilen geliştirme maliyetleri), karşılıklar, koşullu borçlar ve koşullu varlıklar (garanti karşılıkları, dava karşılıkları, gerçekleşmiş ancak rapor edilmemiş tazminat bedelinin tahmini), yatırım amaçlı gayrimenkullerde gerçeğe uygun değer ölçümü ve stokların net gerçekleşebilir değeri olarak sıralanmaktadır.

Tablo 2: 2019 ve 2020 Y1llarında KDK Bölümünde Yer Alan Konular

\begin{tabular}{|l|c|c|c|c|}
\hline \multirow{2}{*}{ Tablo 2: 2019 ve 2020 Yıllarında KDK Bölümünde Yer Alan Konular } & \multicolumn{3}{|c|}{$\mathbf{2 0 1 9}$ Yılı } \\
\cline { 2 - 6 } KDK Kapsamında Açıklanan Konular & Bildirim Sayısı & $\begin{array}{c}\text { Bildirim } \\
\text { Oranı }\end{array}$ & Bildirim Sayısı & $\begin{array}{c}\text { Bildirim } \\
\text { Oranı }\end{array}$ \\
\hline Hasılatın Muhasebeleştirilmesi & 36 & 16.67 & 33 & 16.67 \\
\hline Finansal Araçlar & 34 & 15.74 & 31 & 15.66 \\
\hline Maddi Duran Varlıklar & 22 & 10.19 & 15 & 7.58 \\
\hline Ticari Alacaklar & 18 & 8.33 & 15 & 7.58 \\
\hline Şerefiye Değer Düşüklüğü & 16 & 7.41 & 16 & 8.08 \\
\hline Maddi Olmayan Duran Varlıklar & 15 & 6.94 & 17 & 8.59 \\
\hline Karşıklar, Koşullu Borçlar ve Koşullu Varlıklar & 14 & 6.48 & 12 & 6.06 \\
\hline Yatırım Amaçlı Gayrimenkullerin Değerlemesi & 12 & 5.56 & 11 & 5.56 \\
\hline Stoklar & 11 & 5.09 & 10 & 5.05 \\
\hline Ertelenmiş Vergi & 10 & 4.63 & 6 & 3.03 \\
\hline
\end{tabular}




\begin{tabular}{|c|c|c|c|c|}
\hline Emeklilik Haklarından Doğan Yükümlülükler & 9 & 4.17 & 8 & 4.04 \\
\hline İşletme Birleşmeleri & 6 & 2.78 & 2 & 1.01 \\
\hline Kiralamalar & 5 & 2.31 & 16 & 8.08 \\
\hline Aktifleştirilen Maden Varlıkları & 4 & 1.85 & 2 & 1.01 \\
\hline İşletmenin Sürekliliğinin Değerlendirilmesi & 2 & 0.93 & 1 & 0.51 \\
\hline Borçlanma Maliyetleri & 1 & 0.46 & 1 & 0.51 \\
\hline Ticari Borçlar & 1 & 0.46 & 1 & 0.51 \\
\hline Bilgi Teknolojileri & 0 & 0.00 & 1 & 0.51 \\
\hline
\end{tabular}

Araştırma kapsamındaki BİST-100 şirketlerinin, Borsa İstanbul'un temel sektör sınıflandırması baz alınarak hazırlanan, sektörel dağılımlarına Tablo 3’te yer verilmiştir.

\begin{tabular}{|l|c|}
\hline Tablo 3: BİST-100 Şirketlerinin Sektör Sınıflandırması & Şirket Sayısı \\
\hline SEKTÖRLER & 1 \\
\hline EĞİTİM, SAĞLIK, SPOR VE DİĞER SOSYAL HİZMETLER & 9 \\
\hline ELEKTRİK GAZ VE SU & 43 \\
\hline İMALAT & 1 \\
\hline İNŞAAT VE BAYINDIRLIK İŞLERİ & 2 \\
\hline MADENCİLİK VE TAŞ OCAKÇILIĞI & 28 \\
\hline MALİ KURULUŞLAR & 8 \\
\hline TEKNOLOJI & 6 \\
\hline TOPTAN VE PERAKENDE TİCARET & 2 \\
\hline ULAŞTIRMA, DEPOLAMA VE HABERLEŞME & \\
\hline
\end{tabular}

Çalışma kapsamında yer alan şirketler 9 adet sektör altında sınıflandırılırken, sektörlere göre öne çıkan KDK bildirimleri ayrıca incelenmiştir. Tablo 4’te sektörlere göre KDK kapsamında ağırlıklı olarak açıklanan konulara yer verilmiştir.

Tablo 4: Sektörlere Göre En Çok Açıklanan Kilit Denetim Konuları

\begin{tabular}{|c|c|}
\hline SEKTÖR & Kilit Denetim Konuları \\
\hline \multirow{5}{*}{ İMALAT } & Ticari Alacaklar \\
\hline & Hasılatın Muhasebeleştirilmesi \\
\hline & Şerefiye Değer Düşüklüğü \\
\hline & Stoklar \\
\hline & Finansal Araçlar \\
\hline \multirow{4}{*}{ MALİ KURULUŞLAR } & $\begin{array}{l}\text { Krediler, kiralama işlemlerinden alacaklar ve finans sektöründen alacaklara ilişkin TFRS } 9 \\
\text { çerçevesinde belirlenen beklenen zarar karş1lıkları }\end{array}$ \\
\hline & Yatırım Amaçlı Gayrimenkullerin Değerlemesi \\
\hline & Emekli Sandığı Yükümlülüklerinin Değerlemesi \\
\hline & Şerefiye Değer düşüklüğü \\
\hline \multirow{2}{*}{ TEKNOLOJI } & Hasılatın Muhasebeleştirilmesi \\
\hline & Ticari Alacaklar \\
\hline \multirow{3}{*}{$\begin{array}{l}\text { İNŞAAT VE BAYINDIRLIK } \\
\text { İŞLERİ }\end{array}$} & Hasılatın Muhasebeleştirilmesi \\
\hline & Maddi Duran Varlıklar \\
\hline & Yatırım Amaçlı Gayrimenkullerin Değerlemesi \\
\hline \multirow{3}{*}{$\begin{array}{c}\text { TOPTAN VE PERAKENDE } \\
\text { TİCARET }\end{array}$} & Hasılatın Muhasebeleştirilmesi \\
\hline & Ticari Alacaklar \\
\hline & Kiralamalar \\
\hline \multirow{2}{*}{$\begin{array}{l}\text { EĞİTİM, SAĞLIK, SPOR VE } \\
\text { DİĞER SOSYAL HİZMETLER }\end{array}$} & Hasılatın Muhasebeleştirilmesi \\
\hline & Hastane ruhsatlarının değer düşüklüğü tespiti \\
\hline
\end{tabular}




\begin{tabular}{|c|l|}
\hline \multirow{2}{*}{$\begin{array}{c}\text { ELEKTRIKK GAZ VE SU } \\
\text { MADENCILIK VE TAŞ } \\
\text { OCAKÇILIĞI }\end{array}$} & Hasılatın Muhasebeleştirilmesi \\
\cline { 2 - 2 } & Ticari Alacaklar \\
\cline { 2 - 2 } $\begin{array}{c}\text { ULAŞTIRMA, DEPOLAMA VE } \\
\text { HABERLEŞME }\end{array}$ & Aktifleştirilen Maden Varlıkları \\
\hline & Sak uçuş programı yükümlülüğünün muhasebeleştirilmesi \\
\cline { 2 - 2 } & Maddi Duran Varlıklar \\
\cline { 2 - 2 } & Teslim Bakım Karşılıkları \\
\hline
\end{tabular}

Tablo 5, KDK kapsamında bildirilen önemli muhasebe tahmin ve varsayımlarının sayısını ve 2019 ile 2020 arasındaki yüzdesel değişimi göstermektedir. 2019 ve 2020 yıllarında KDK kapsamında açıklanan muhasebe tahmin ve varsayımlarında ilk sırada gerçeğe uygun değer ölçümü yer almaktadır. 2019 yılında KDK içinde gerçeğe uygun değer açıklamaları sayısı 28 iken, bu sayının 2020 yılında 36’ya çıkarak \%28 oranında arttı̆̆ı görülmektedir. Bu kapsamda, finansal varlık ve yükümlülüklerin, finansal yatırımların, yatırım amaçlı gayrimenkullerin ve maddi duran varlıkların gerçeğe uygun değer ölçümlerine ilişkin açıklamalara yer verildiği görülmektedir. KDK kapsamında açıklanan muhasebe tahmin ve varsayımlarında ikinci sırada hasılatın muhasebeleştirilmesi yer almaktadır. Hasılatın muhasebeleştirilmesi kapsamında imalat işletmelerinde en çok vurgulanan konu, edim yükümlülüğünün yerine getirilip getirilmediğin tahmininde yaşanan sorunlara bağlı olarak hasılatın döneminin tespiti problemi yer almaktadır. İnşaat şirketleri, gayrimenkul yatırım ortaklıkları, holdingler ve yatırım işletmelerinde bu kapsamda en çok açıklanan konu ise tamamlanma yüzdesinin hesaplanması ve toplam proje maliyetinin belirlenmesine yönelik tahminlerde yaşanan zorluklardır. Enerji sektöründe, görevli tedarikçi firmaların gelirlerinin tahmine dayalı olarak muhasebeleştirilmesinden kaynaklanan risk vurgulanırken, finansal kuruluşlarda uzun vadeli sözleşmelerde hasılatın finansal tablolara alınmasına ilişkin risklere vurgu yapılmıştır.

\begin{tabular}{|c|c|c|c|}
\hline Önemli Tahmin ve Varsayımlar & 2020 & 2019 & Yüzdesel Değişim \% \\
\hline Gerçeğe Uygun Değer Ölçümü & 36 & 28 & 28.57 \\
\hline Hasılatın Muhasebeleştirilmesi & 22 & 19 & 15.79 \\
\hline Şerefiye Değer Düşüklüğü & 16 & 16 & 0.00 \\
\hline TFRS 9 Kapsamında Beklenen Kredi Zararlarına İlişkin Karşılıklar & 14 & 13 & 7.69 \\
\hline Karş1lıklar, Koşullu Borçlar ve Koşullu Varlıklar & 14 & 12 & 16.67 \\
\hline Ticari Alacakların Geri Kazanılabilirliği & 14 & 12 & 16.67 \\
\hline Maddi Duran Varlık Değer Düşüklüğü & 12 & 9 & 33.33 \\
\hline Stokların Net Gerçekleşebilir Değerinin Tespiti & 11 & 10 & 10.00 \\
\hline Ertelenmiş Vergi Varlığının Geri Kazanılabilirliği & 10 & 6 & 66.67 \\
\hline Emeklilik Haklarından Doğan Yükümlülükler & 9 & 8 & 12.50 \\
\hline Maddi Olmayan Duran Varlıklarda Değer Düşüklüğü & 9 & 9 & 0.00 \\
\hline Aktifleştirilen Geliştirme Maliyetleri & 5 & 7 & -28.57 \\
\hline Aktifleştirilen Maden Varlıkları & 4 & 2 & 100.00 \\
\hline İşletmenin Sürekliliğinin Değerlendirilmesi & 1 & 0 & \\
\hline TOPLAM & 177 & 151 & $\mathbf{1 7 . 2 2}$ \\
\hline
\end{tabular}

KDK kapsamında açıklanan muhasebe tahmin ve varsayımlarında 2019-2020 yılları arasında en yüksek oranda değişim ise ertelenmiş vergi varlıklarının geri kazanabilirliği konusunda ortaya çıkmıştır. Bir işletmede işletmenin sürekliliğinin değerlendirmesi KDK kapsamında yer alırken, konu ile ilgili açıklamada COVID-19 nedeniyle yaşanan kapanmanın nakit akış tahmini üzerindeki olumsuz etkisi vurgulanmaktadır.

\section{Sonuç ve Tartışma}

Bağımsız denetim raporlarına KDK bölümünün eklenmesinin amacı, işletmeler ve rapor kullanıcıları arasındaki iletişimi artırmak, raporlarda riskli görülen hususların altını çizmek ve böylece daha şeffaf ve kaliteli raporların ortaya çımasını sağlamaktır. Literatürdeki bazı araştırmalar KDK içeren yeni tip bağımsız denetim raporlarının amacını gerçekleştirmek 
adına yetersiz kaldığı yönündeki bulgulara ulaşsa da, geçmiş çalışmaların sonuçlarına göre raporlara ilişkin genel beklentinin ve algının olumlu olduğu ortaya çıkmaktadır.

Bu çalışma kapsamında BİST-100 şirketlerinin 2019 ve 2020 yıllarına ait KDK açıklamaları incelenmiştir. 2019 yılında 198 adet KDK bildirimi tespit edilirken, 2020 yılı bildirim sayısının ise 216 olduğu görülmüştür. İncelemeye tabi şirketlerin ağırlıklı kısmı Big4 firmaları tarafından denetlenmektedir. Raporlarda yer alan KDK bildirimlerinin denetçi firmaya ya da denetim görüşüne bağlı olarak değişmediği görülmektedir. Aynı denetim şirketine ait raporlar karşılaştırıldığında, format olarak benzerlikler tespit edilmiş olmakla birlikte, raporların işletmelere özgü bilgiler içerdiği görülmüştür. 2019 ve 2020 yıllarında KDK içinde ön plana çıkan konular benzerlik göstermekte olup, bunların en ağırlıklı olanları; hasılatın muhasebeleştirilmesi, finansal araçlar ve maddi duran varlıklardır. 2019 yılında TFRS 16 kiralamalar standardı kapsamındaki açıklamaların KDK içindeki payı \%8 iken, 2020 yılında \%2’ye gerilediği görülmektedir. Bu durum KDK açıklamalarının finansal raporlama standartlarındaki değişikliklerden etkilendiğini düşündürmektedir. Ayrıca KDK kapsamında değerlendirilen konuların sektörlere göre ayrımı incelendiğinde, bazı konuların hemen hemen her sektör için önem arz ettiği, ancak bazı sektörel farkların da öne çıktığı görülmektedir.

Muhasebe tahminleri doğası gereği belirsizlik içerdiği için, belirsizlik ortamından en çok etkilenecek konuların da yine muhasebe tahminleri olması beklenmektedir. Bu bağlamda, KDK içindeki muhasebe tahmin ve varsayımlarının payı yıllar itibariyle ayrıca incelenmiş olup, muhasebe tahminlerinin KDK içindeki payının 2020 yılında, 2019 yılına göre \% 28 oranında arttı̆̆ görülmektedir. Muhasebe tahminlerine dayanan konular içinde KDK kapsamında en çok bildirilen ise gerçeğe uygun değer ölçümüdür. COVID-19 pandemi dönemi günümüzde devam etmekte ve pandeminin ekonomik ve sosyal etkilerinin zaman içinde daha fazla ortaya çıkacağı beklentisi bulunmaktadır. Bu nedenle COVID-19 pandemisinin KDK kapsamında değerlendirilen konulara etkisinin de günden güne derinleşebileceği düşünülmektedir. Çalışma sadece BİST-100 şirketleri ile sınırlandırılmış. Gelecek dönemlerde daha geniş bir örneklem ve zaman aralı̆̆ını kapsayan veri grubuyla çalışmanın geliştirilebileceği, aynı zamanda pandeminin bağımsız denetim raporları üzerindeki etkisinin çok boyutlu olarak ele alınarak, rapor kullanıcılarına yardımcı olabilecek önemli bilgilere ulaşılabileceği düşünülmektedir.

Hakem Değerlendirmesi: Dış bağımsız.

Çıkar Çatışması: Yazar çıkar çatışması bildirmemiştir.

Finansal Destek: Yazarlar finansal destek beyan etmemişlerdir.

Peer-review: Externally peer-reviewed.

Conflict of Interest: The author has no conflict of interest to declare.

Financial Disclosure: Authors declared no financial support.

\section{Kaynaklar}

Akdoğan, N. ve Bülbül, S. (2019). Bağımsız denetçi raporlarında kilit denetim konularının bildirilmesinde BİST 100 şirketlerindeki ilk uygulama sonuçlarının değerlendirmesine yönelik bir araştırma. Muhasebe ve Denetime Bakış, 56, 1-24.

Akdoğan, N. ve Kılıç, G. (2021). Borsa İstanbul (BİST) şirketlerinin 2019 yılındaki denetim görüşleri, bağımsız denetçi raporlarında verilen görüşün dayanağı ve kilit denetim konularının incelenmesine yönelik bir araştırma. Muhasebe ve Denetime Bakış, 64, 1-18.

Bağımsız Denetim Raporu (BDS) 200. Bağımsız Denetçinin Genel Amaçları ve Bağımsız Denetimin Bağımsız Denetim Standartlarına Uygun Olarak Yürütülmesi. https://kgk.gov.tr/Portalv2Uploads/files/Duyurular/v2/TDS/TDS_2021_Seti/BDS\%20200.pdf

Bağımsız Denetim Raporu (BDS) 701. Kilit Denetim Konularının Bağımsız Denetçi Raporunda Bildirilmesi. https://kgk.gov.tr/ Portalv2Uploads/files/Duyurular/v2/TDS/TDS_2021_Seti/BDS\%20701.pdf

Bédard, J., Gonthier- Besacier, .B., \& Schatt, A. (2014). Costs and benefits of reporting key audit matters in the audit report: The French experience. Working Paper, (January), 1-24. https://www.isarhq.org/2014_downloads/papers/ISAR2014_Bedard_Besacier_Schatt.pdf.

Christensen, B. E., Glover, S. M., \& Wolfe, C. J. (2014). Do critical audit matter paragraphs in the audit report change nonprofessional investors' decision to invest?. Auditing: A Journal of Practice \& Theory, 33(4), 71-93. 
Ciğer, A., Vardar, G.Ç. ve Kınay, B. (2019). Bağımsız denetçi raporlarında yer alan kilit denetim konularının analizi: Borsa İstanbul örneği. Mali Çözüm Dergisi, 29(153), 109-148.

Coram, P.J., \& Wang, L. (2020). The effect of disclosing key audit matters and accounting standard precision on the audit expectation gap. International Journal of Accounting, 25(2), 270-282.

Cordoş, G.S., \& Fülop, M.T. (2015). Understanding audit reporting changes: introduction of key audit matters. Accounting and Management Information Systems, 14(1), 128-152.

Erdem, B. (2020). Finansal tablolardaki hile olasılığının kilit denetim konularına etkisi: Borsa İstanbul'da bir analiz. Esam Ekonomik Ve Sosyal Araştırmalar Dergisi, 1(2), 245-260.

Fera, P., Pizzo, M., Vinciguerra, R., \& Ricciardi, G. (2021). Sustainable corporate governance and new auditing issues: a preliminary empirical evidence on key audit matters. Corporate Governance, September (Advance online publication).

Ferreira, C., \& Morais, A.I. (2019). Analysis of the relationship between company characteristics and key audit matters disclosed. Revista Contabilidade \& Finanças, 31(83), 262-274.

Gold, A., \& Heilmann, M. (2019). The consequences of disclosing key audit matters (KAMs): A review of the academic literature. Maandblad voor Accountancy en Bedrijfseconomie, 93(1/2), 5-14.

Gold, A., Heilmann, M., Pott, C., \& Rematzki, J. (2020). Do key audit matters impact financial reporting behavior?. International Journal of Auditing, 24(2), 232-244.

Gökgöz, A. (2018). Kilit denetim konularının bağımsız denetçi raporunda bildirilmesi ve Borsa İstanbul'da işlem gören işletmeler üzerine bir araştırma. Journal of Acoounting, Finance and Auditing Studies, 4 (2), 126-138.

ISA 700. (2015). Forming an opinion and reporting on Financial statements. https://www.ifac.org/system/files/publications/files/ISA700-Revised_8.pdf

ISA 701. (2015). Communicating Key audit matters in the independent auditor's report. https://www.ifac.org/system/files/publications/ files/ISA-701_2.pdf

Karacan, S. ve Uygun, R. (2018). Kilit denetim konularının bağımsız denetçi raporunda bildirilmesi - BDS 701. Uluslararası Sosyal Araştırmalar Dergisi / The Journal of International Social Research, 11(57), 632-649.

Kavut, F. L. ve Güngör, N. (2018). Bağımsız denetimde kilit denetim konuları: BİST-100 şirketlerinin 2017 yılı analizi. Muhasebe Enstitüsü Dergisi, 16(59), 59-70.

KGK (2021). Muhasebe Tahminleri Tanımı- TMS 8'e İlişkin Değişiklikler. https://kgk.gov.tr/Portalv2Uploads/files/Duyurular/v2/TMS/ Ek\%204.pdf. (Erişim Tarihi: 09.09.2021).

Kitiwong, W., \& Sarapaivanich, N. (2020). Consequences of the implementation of expanded audit reports with key audit matters (KAMs) on audit quality. Managerial Auditing Journal, 35(8), 1095-1119.

Lau, C.K. (2021). Measurement uncertainty and management bias in accounting estimates: the perspective of key audit matters reported by Chinese firms' auditors. Asian Review of Accounting, 29(1), 79-95.

Pinello, A., Puschaver, L., \& Volkan, A. (2020). The relationship between critical accounting estimates and critical audit matters. Accounting \& Taxation, 12(1), 23-33.

Sarısoy, Ö. (2021). Kritik/kilit denetim konularının BİST 30 ve Dow Jones 30 endekslerindeki işletmelerin denetçi raporları üzerinden karşılaştırılması. Muhasebe ve Denetime Bakış, 63, 159-182.

Sarısoy, Ö. ve Kepçe, N. (2019). Bağımsız denetim raporunda kilit denetim konularına yer verilmesi ve beklenti farkları. Mali Çözüm Dergisi, 29(153), 39-66.

Süer, A. (2021). Önemli muhasebe tahminlerinin kilit denetim konuları çerçevesinde incelenmesi. Muhasebe Enstitüsü Dergisi, 65, 23 -37.

Türel, A. ve Türel A. (2019). Bağımsız denetim ve kilit denetim konuları: BİST şirketleri 2017-2018 analizi. Journal of International Social Research, 12(68), 1267-1272.

Yanık S. ve Karataş, M. (2017). Denetim raporlarının geleceği: yeni düzenlemeler ve ülke uygulamaları. Muhasebe ve Finansman Dergisi. Ocak, 1-26. 
EK 1:

Tablo 6: Çalışma Kapsamında İncelenen BİST-100 Şirketleri

1. AFYON ĊIMENTO SAN. T.A.S.

2. ANADOLU GRUBU HOLDING A.Ş.

3. AKBANK T.A.S.

4. AKÇANSA ÇIMMENTO SANAYİ VE TİCARET A.Ş.

5. AKSA AKRİLİK KIMYA SANAYIII A.S.

6. AKSA ENERJI ÜRETIM A.Ş.

7. ALARKO GAYRIMENKUL YATIRIM ORTAK. A.Ş.

8. ALARKO HOLDING A.Ş.

9. ALBARAKA TÜRK KATILIM BANKASI A.Ş.

10. ALKİM ALKALİ KİMYA A.Ş.

11. ANADOLU EFES BİRACILIK VE MALT SAN. A.S.

12. ARÇELIKK A.Ş.

13. ARD GRUP BILISSIMM TEKNOLOJILERİ A.S.

14. ASELSAN ELEKTRONIK SANAYI VE TİC. A.Ş.

15. AYDEM YENIILENEBİLİR ENERJİ A.Ş.

16. AYGAZ A.S.

17. BERA HOLDING A.S.

18. BIMM BIRLEŞIK MAĞ́AZALAR A.S

19. BIOOTREND CCEVRE VE ENERJI YATIRIM. A.Ș.

20. BRISAA BRIDGESTONE SABANCI LASTIKK SANAYİ VE TICARET A.S.

21. COCA-COLA İCECEK A.S .

22. ÇAN2 TERMIKK A.Ş.

23. CEMTAS CELIK MAKINA SANAYİ VE TİC. A.S.

24. ÇIMSA ÇIMMENTO SANAYİ VE TICARET A.Ş.

25. DEVA HOLDING A.S.

26. DOĞAN ŞİRKETLER GRUBU HOLDINNG A.Ş.

27. DOĞUŞ OTOMOTIV SERVIS VE TICARET A.Ş.

28. EGE ENDÜSTRI VE TICARET A.Ş.

29. ECZACIBASI İLAC SINAİ VE FINANSAL YATIRIMLAR SANAYİ VE TİCARET A.Ş.

30. EMLAK KONUT GAYRIMENKUL YATIRIM ORTAKLIĞI A.Ş.

31. ENERJISA ENERJİ A.S

32. ENKA İNŞAAT VE SANAYİ A.Ş.

33. ERBOSAN ERCIYAS BORU SANAYIII VE TİCARET A.S.

34. EREĞLI DEMIR VE ÇELIKK FABRIKALARI T.A.Ş.

35. ESENBOĞA ELEKTRIK ÜRETIMM A.S.

36. FORD OTOMOTIV SANAYİ A.Ş.

37. GLOBAL YATIRIM HOLDING A.Ş.

38. GÜBRE FABRIKALARI T.A.S.

39. HACI ÖMER SABANCI HOLDİNG A.S.

40. HALK GAYRIMENKUL YATIRIM ORTAK. A.Ș.

41. HEKTAŞ TÍCARET T.A.Ş.

42. İNDEKS BİLGISSAYAR SISTEMLERİ MÜHENDİSLIK SANAYI VE TICARET A.Ş.

43. İSKENDERUN DEMIR VE ÇELIK A.S.

44. İS FINANSAL KİRALAMA A.Ş.

45. İS GAYRIMMENKUL YATIRIM ORTAKLIĞI A.S.

46. İŞ YATIRIM MENKUL DEĞERLER A.Ş.

47. İZMIR DEMIR CELIK SANAYİ A.S.

48. KARDEMIR KARABÜK DEMIR ÇELIK SANAYI VE

TICARET A.S.

49. KARSAN OTOMOTIV SANAYIII VE TİCARET A.Ş.

50. KARTONSAN KARTON SANAYİ VE TİC. A.S.
51. KEREVITAS GIDA SANAYİ VE TİCARET A.S.

52. KERVAN GIDA SANAYI VE TİCARET A.Ş.

53. KOC HOLDING A.S.

54. KORDSA TEKNIK TEKSTIL A.Ş.

55. KOZA ALTIN İSLETMELERİ A.S.

56. KOZA ANADOLU METAL MADENCILLIK IŞLETMELERİ A.S.

57. LOGO YAZILIM SANAYİ VE TİCARET A.Ş.

58. MAVİ GIYIMM SANAYİ VE TİCARET A.Ș.

59. MIGROS TICARET A.Ş.

60. MLP SAĞLIK HİZMETLERİ A.Ș.

61. NETAŞ TELEKOMÜNIKASYON A.Ş.

62. SODAŞ ELEKTRIKK ÜRETIM SANAYİ TİC. A.S.

63. OTOKAR OTOMOTIV VE SAVUNMA SAN. A.Ş.

64. OYAK ÇIMENTO FABRIKKALARI A.Ş.

65. PARSAN MAKINA PARÇALARI SANAYIII A.Ş.

66. PEGASUS HAVA TAȘIMACILIĞI A.Ş.

67. PETKIM PETROKIMYA HOLDING A.S

68.QUA GRANITE HAYAL YAPI VE ÜRÜNLERİ SANAYİ

TÍCARET A.S.

69. SARKUYSAN ELEKTROLITIK BAKIR SANAYİ VE

TICARET A.S.

70. SASA POLYESTER SANAYİA.Ş.

71. SELCUK ECZA DEPOSU TICARET VE SAN. A.S.

72. ŞEKERBANK T.A.Ş.

73. SOK MARKETLER TICARET A.S

74. TAV HAVALIMANLARI HOLDİNG A.Ş.

75. TEKFEN HOLDING A.S.

76. TEKNOSA İÇ VE DIŞ TİCARET A.Ş.

77. TOFAS TÜRK OTOMOBIL FABRIKKASI A.Ș.

78. TORUNLAR GAYRIMENKUL YATIRIM ORTAKLIĞI A.Ş.

79. TURK İLAC VE SERUM SANAYİ A.S.

80. TURKCELL İLETIŞIIM HIZZMETLERİ A.Ş.

81. TÜMOSAN MOTOR VE TRAKTÖR SANAYİ A.S.

82. TÜPRAŞ-TÜRKIYYE PETROL RAFINERILERİ A.Ş.

83. TÜRK HAVA YOLLARI A.O.

84. TÜRK TELEKOMÜNIKASYON A.Ş.

85. TÜRK TRAKTÖR VE ZIRAAT MAKİNELERİ A.S,.

86. TÜRKIYE GARANTİ BANKASI A.Ş.

87. TÜRKIYYE HALK BANKASI A.S.S.

88. TÜRKIYY İŞ BANKASI A.S.

89. TÜRKIYYE SINAİ KALKINMA BANKASI A.Ş.

90. TÜRKIYE SIGGORTA A.S..

91. TÜRKIYYE ŞIŞE VE CAM FABRIKKALARI A.Ş.

92. TÜRKIYE VAKIFLAR BANKASI T.A.O.

93. ÜLKER BİSKÜVİ SANAYİ A.Ş.

94. VERUSA HOLDING A.S.

95. VESTEL BEYAZ EŞYA SANAYİ VE TİCARET A.Ş.

96. VESTEL ELEKTRONIK SANAYI VE TICARET A.S

97. YAPI VE KREDİ BANKASI A.Ş.

98.YATAS YATAK VE YORGAN SANAYI VE TICCARET A.S.

E 99. ZIRAAT GAYRIMENKUL YAT. ORTAKLIĞI A.Ş.

100. ZORLU ENERJI ELEKTRİK ÜRETIM A.S. 
Tablo 7: Çalışma Kapsamındaki İşletmelerin Bağımsız Denetim Firmaları ve Denetlenen Şirket Sayıları

\section{Bağımsız Denetim Firmaları}

Abaküs Bağımsız Denetim A.Ş.

Aday Bağımsız Denetim ve Serbest Muhasebeci Mali

Müşavirlik A.Ş.

Aksis Uluslararası Bağımsız Denetim A.Ş.

Arkan Ergin Uluslararası Bağımsız Denetim A.Ş.

Ban-Den Bağımsız Denetim Hizmetleri A.Ş.

BDO Denet Bağımsız Denetim Ve Danışmanlık A.Ş.

DRT Bağımsız Denetim ve Serbest Muhasebeci Mali

Müşavirlik A.Ş. (DELOITTE)

Eren Bağımsız Denetim A.Ş

Finansal Eksen Bağımsız Denetim ve Danışmanlık A.Ş.

Güney Bağımsız Denetim ve SMMM A.Ş. (EY)

Güreli Yeminli Mali Müşavirlik ve Bağımsız Denetim

Hizmetleri A.Ş.

Karar Bağımsız Denetim ve Danışmanlık A.Ş.

Köker Yeminli Mali Müşavirlik ve Bağımsız Denetim A.Ş.

KPMG Bağımsız Denetim ve Serbest Muhasebeci Mali Müşavirlik A.Ş.

Mega Global Uluslararası Bağımsız Denetim A.Ş.

Mercek Bağımsız Denetim ve Yeminli Mali Müşavirlik A.Ş.

PwC Bağımsız Denetim ve Serbest Muhasebeci Mali

Müşavirlik A.Ş.

Rasyonel Bağımsız Denetim ve Yeminli Mali Müşavirlik A.Ş.

Yeditepe Bağımsız Denetim ve Yeminli Mali Müşavirlik A.Ş.

\begin{tabular}{|c|c|}
\hline \multicolumn{2}{|c|}{ Denetlenen Şirket Sayıları } \\
\hline 2020 & 2019 \\
\hline 1 & 0 \\
\hline 2 & 2 \\
\hline 1 & 1 \\
\hline 2 & 2 \\
\hline 1 & 1 \\
\hline 2 & 2 \\
\hline 14 & 15 \\
\hline 5 & 2 \\
\hline 1 & 0 \\
\hline 22 & 21 \\
\hline 2 & 3 \\
\hline 0 & 1 \\
\hline 1 & 0 \\
\hline 14 & 14 \\
\hline 0 & 2 \\
\hline 0 & 1 \\
\hline 31 & 27 \\
\hline 0 & 3 \\
\hline 1 & 1 \\
\hline
\end{tabular}


